(Q) Can the indefinite object of an extensional verb be non-specific in a will-sentence? ${ }^{2}$

\section{The interpretation of indefinites in future tense sentences: A novel argument for the modality of will?}

\author{
FABIO DEL PRETE
}

\subsection{INTRODUCTION}

In this chapter I reconsider the thorny issue of whether the future auxiliary will should be regarded as a tense or as a modal, by focusing on the interpretation of indefinite noun phrases in will-sentences. A distinction that will play a key role is the one between specific and non-specific (interpretations of) indefinites, illustrated in (1a)-(1c):

(1) a. Mary is trying to find a book on modality.

b. $\exists x\left[\right.$ book-on-modality $(x) \wedge \operatorname{try}\left(\operatorname{Mary},{ }^{\wedge}\right.$ find $\left.\left.(\operatorname{Mary}, x)\right)\right]$

'There is a particular book on modality that Mary is trying to find.'

c. $\operatorname{try}($ Mary, $\wedge \exists x[$ book-on-modality $(x) \wedge$ find $($ Mary, $x)])$

'Mary is trying to find some book on modality or other.'

The indefinite is specific in (1b), the characteristic feature of this interpretation being that a certain book corresponds to the NP. By contrast, it is non-specific in (Ic), as there is no particular book semantically related to the NP on this interpretation. ${ }^{1}$

The main question that I will address is the following:

1 The distinction between specific and non-specific indefinites, as I make use of it in this chapter, is not intended to imply that the English determiner $a$ is lexically ambiguous. In particular, it should not be understood in terms of the semantic opposition 'referential' versus 'quantificational' indefinites in the sense of Fodor and Sag (1982). The way I intend it is as a surfacy semantic distinction, one which is in fact compatible with a uniform analysis of indefinttes as existential quantifiers, as will be proposed in Section 1.3 .5 .
The idea behind the argument is simple: if will is a modal (hence an intensional) operator, it should be able to give rise to non-specific indefinites in object position, as the intensional predicate is trying to does in (1a). We will see that will does give rise to non-specific indefinites, although to ones that, at the surface, seem to differ from non-specific indefinites of the more familiar sort, for which wide scope existential quantification of the indefinite's variable (for short, WSE) blatantly fails. To detect this sort of non-specific indefinite, other tests are needed, and I will discuss some relevant linguistic data in the following sections.

The structure of the chapter is as follows. In Section 3.2 I introduce Stalnaker's Asymmetry, the prima facie observation that the inferences in (2) and (3) differ in logical status: the former is valid only under a reading of its premise in which the president's obligation is in relation to a certain woman-WSE fails as a general inference rule in this case; the validity of the latter, however, does not seem to depend on a particular interpretation of the premise in a similar way-WSE seems to be validly applicable as a general inference rule there. ${ }^{3}$

(2) a. President Carter has to appoint a woman to the Supreme Court.

b. Therefore, there is a particular woman that the president has to appoint.

(3) a. President Carter will appoint a woman to the Supreme Court.

b. Therefore, there is a particular woman that the president will appoint.

From Stalnaker's Asymmetry, I provisionally conclude that (Q) has a negative answer. In Section 3.3 some data are presented which question this conclusion. At first, I consider the interpretation of discourses like (4):

(4) Mary wants to marry a rich man. He must be a banker. [Karttunen 1976]

As Karttunen (1976) remarks, (4) is ambiguous between two readings: the specific interpretation of a rich man correlates with the epistemic interpretation of must, while

2. The attention in (Q) is restricted to extensional verbs for an obvious reason. Indefinite objects of intensional verbs can naturally obtain non-specific interpretations, both in past and in future tense contexts, as shown in (i) and (ii):

(i) Mary looked for a book on modality, but she didn't find one.

('Mary looked for some book on modality or other, but she didn't find any such book.)

(ii) Mary will look for a book on modality, but she won't find one.

('Mary will look for some book on modality or other, but she won't find any such book.')

The non-specific interpretation of a book on modality in (i) and (ii) has the same source; it depends on the intensionality of the verb look for, thus it does not tell us anything about whether the future tense itself has vome intensional feature that maken it possible for the indefinite to be interpreted non-specifically

i Sentences (2a) and (aia) are from Stalnaker ( $\left.10 \mathrm{~g}_{1}\right)$ 
the non-specific interpretation of the indefinite is associated with a deontic-like interpretation of the modal, described later on as teleological. ${ }^{4}$ I observe that the variant of (4) with will in the place of want does not seem to allow for a reading in which a rich man is non-specific and must teleological:

(5) Mary will marry a rich man. He must be a banker.

While this conforms with the provisional conclusion from Section 3.2, I then show that we do find Karttunen-type discourses with will followed by must, in which must is teleological; furthermore, as we switch from must to should, it becomes easier to observe a parallel between want and will, as in discourses (6) and (7), both displaying the teleological interpretation of should:

(6) Mary wants to marry a rich man. He should be a banker.

(7) Mary will marry a rich man. He should be a banker.

In Section 3.4 I examine the possibility that the teleological interpretation of the modal would not require non-specificity of the indefinite in the will-sentence but a weaker condition of ignorance of the actual referent's identity. Here I argue that there is genuine non-specificity and make a preliminary informal suggestion to explain away the prima facie contrast between non-specificity of the indefinite object and some critical data at the basis of Stalnaker's Asymmetry. In Section 3.5 a formal analysis of will is proposed on which its basic semantic contribution is that of a tense, as conceived in referential/presuppositional analyses (e.g. Heim 1994): a temporal variable whose value is presupposed to be a situation in the future of the utterance situation. A central assump tion is that speakers represent the future state of the world as open to themselves, in terms of a plurality of possible futures branching off from the present situation; this is reflected in the interpretation model, a variant of classical Branching Time (Thomason 1984; Belnap et al, 2001). All these possible futures are assumed to be equally eligible candidates for the truth-conditional evaluation of a will-statement. I further assume that, on top of will's basic semantics, a default universal quantification over the domain of possible futures comes into play as a supervaluational strategy to overcome

${ }^{4}$ Karttunen (2007) speaks of 'epistemic' and 'deontic' interpretation of must when he refers to the interpretations of (i.a) given in (i.b) and (i.c), respectively:

(i) a. The director is looking for an innocent blonde. She must be 17 years old.

b. The director is looking for an innocent blonde. It is likely that she is 17 years old.

c. The director is looking for an innocent blonde. It is necessary that she be 17 years old.

Following a suggestion by an anonymous reviewer, I will adopt the different term 'teleological' to refer to the interpretation of must in (i.c), exploiting the intuition that this reading can be paraphrased as 'to be eligible to be picked up by the director, a blonde must be seventeen years old' I will reserve the term 'deontic' for the interpretation of must in sentences like (ii) instead:

(ii) John must return the book to the library by October 15 th their plurality. This quantification introduces a modal feature in the interpretation of will, which accounts for the relation of modal dependence between will and a subsequent teleological modal should/must. Furthermore, from the assumption that this quantification is due to a supervaluational strategy, it follows that it invariantly takes maximum scope. The lack of scope interactions between the quantifier over futures and the existential quantifier of the indefinite provides the key to explain why Stalnaker's Asymmetry arises. In Section 3.6 I address the issue of the theoretical status of the supervaluational strategy, and discuss some general consequences of the proposed analysis with regard to the interaction between semantics and pragmatics. Section 3.7 concludes.

\subsection{STALNAKER'S ASYMMETRY}

Against an intensional analysis of will as a modal of necessity, one could argue that the answer to our initial question (Can the indefinite object of an extensional verb be nonspecific in a will-sentence?) is negative, based on the contrast between the dialogues (8) and (9): 5

(8) X: President Carter has to appoint a woman to the Supreme Court.

Y: Who do you think he has to appoint?

$\mathrm{X}$ : He doesn't have to appoint any particular woman; he just has to appoint some woman or other.

(9) X: President Carter will appoint a woman to the Supreme Court.

Y: Who do you think he will appoint?

$\mathrm{X}$ : He won't appoint any particular woman; he just will appoint some woman or other.

In dialogue (8), 'Y gives the quantified expression a woman wide scope in interpreting X's statement. X, in his response to $Y$, shows that he meant the quantifier to have narrow scope.' The acceptability of X's answer shows that the indefinite can indeed be interpreted in the semantic scope of the necessity modal in this case, hence nonspecifically. X's response in dialogue (9), on the other hand, is obviously non-sense. There must be a particular person that [the president] will appoint, although the speaker need not know who it is.?

3 Both dialogues are from Stalnaker (1981: 93-4).

6 Stalnaker (1981: 93). In the same passage Stalnaker also remarks that the ambiguity between the tworeadings of a woman in (8) 'is of course not a matter of whether' the speaker knows who the woman is $X$ might have meant the wide scope reading and still not have known who the woman is' 1 will return in Cectien 14 to the g supposed non specific readings of indefinites in will-sentence

Stalnaker (1981 94) 
Following Stalnaker's line, of reasoning, we can submit that there is a contrast in logical status between the inference in (10) and the one in (11):

(10) a. The president will appoint a woman.

b. Therefore, there is a particular woman that he will appoint.

(11) a. The president has to appoint a woman.

b. Therefore, there is a particular woman that he has to appoint.

On the one hand, for (10a) to be true there should be a particular woman of whom it is true that the president will appoint her at some point. We may not know who that particular woman is, the president himself may not know her identity; in principle, the woman may even not have been born yet. Still, the truth of (10a) appears to require that there is (in a temporally unrestricted sense) a particular woman that the president will appoint. On the other hand, for (11a) to be true there need not be a particular woman of whom it is true that the president has to appoint her. Accordingly, if we take the quantificational idiom there is in (10b) and (11b) to express temporally unrestricted quantification (over a domain which includes future individuals, as well as present ones), we regard the inference in (10) as unconditionally valid, whereas the validity of the inference in (11) is seen as contingent upon a construal of the premise in which the indefinite $a$ woman is interpreted specifically-indeed, only on the specific interpretation is there a particular individual semantically related to the indefinite. Crucially, the premise (11a) has an alternative reading, one in which the president's obligations could be fulfilled by his appointing anyone of different women. On the latter interpretation, there is no particular individual corresponding to the indefinite, and the inference in (11) does not go through. I will refer to the prima facie contrast between the unconditional validity of (10) and the conditional validity of (11) as Stalnaker's Asymmetry.

As suggested by Stalnaker's description of dialogue (8) quoted above, the envisaged ambiguity of (11a) could be explained by assuming a standard, Hintikka (1962)-style account of have to as a universal quantifier over possible worlds: the possible worlds in which all the obligations that the president has in the actual world are fulfilled-the president's deontic alternatives with respect to the actual world $w_{0}$. If the modal have to expresses universal quantification over such deontic alternatives, the contrast between the two readings of (11a) can be explained in terms of a scope interaction between the universal quantifier corresponding to the modal verb and the existential quantifier corresponding to the indefinite. On the specific construal, it is the same woman that is picked out across different deontic alternatives, and this is captured by the wide scope construal of the indefinite, given in (12a). On the non-specific construal, different women can be selected relative to different alternatives, and this is captured by the narrow scope construal of the indefinite, given in (12b).
(12) a. $\exists x\left[\operatorname{woman}\left(x, w_{0}\right) \wedge \forall w\left[\operatorname{Altdeontic}\left(w_{0}, w\right.\right.\right.$, Carter $\left.\left.) \rightarrow \operatorname{appoint}(\operatorname{Carter}, x, w)\right]\right]$

b. $\forall w\left[\operatorname{Altdeontic}\left(w_{0}, w\right.\right.$, Carter $) \rightarrow \exists x[\operatorname{woman}(x, w) \wedge$ appoint(Carter, $\left.\left.x, w)\right]\right]^{8}$

Now, if will too were to introduce universal quantification over a domain of modal alternatives, the same ambiguity should be present in (10a) as has been found in (11a), and the validity of the inference in (10) should also be contingent on the specific construal of its premise. But (10) appears to be unconditionally valid. The conclusion, by modus tollens, is that the auxiliary will, unlike the modal verb have to, does not introduce universal quantification over alternatives.

The obvious possibility that one could consider at this point is that will should be analysed as an extensional tense operator, on a par with the past tense morphology. The semantics of will should thus be thought of in terms of existential quantification over times. ${ }^{9}$ The unconditional validity of (10) would thus be explained as follows: (10a) says that there is a time $t_{1}$ such that $t_{1}$ follows the time of utterance $t_{0}$ and the president appoints a woman at $t_{1}$; but from this it follows that there is (in a temporally unrestricted sense) a woman $x$ such that there is a time $t_{1}$ following $t_{\mathrm{o}}$ such that the president appoints $x$ at $t_{1}$, and this is exactly what the conclusion (1ob) says. This theory, however, could not be the whole story about will. We will see why in the next section.

\subsection{MODAL SUBORDINATION IN KARTTUNEN-TYPE DISCOURSES}

Karttunen (1976) observes a correlation between the specific/non-specific interpretation of the indefinite a rich man and the type of interpretation of the modal must in discourses like (13) (where we intend that the pronominal subject of the must-sentence is anaphorically related to the indefinite $a$ rich man): ${ }^{10}$

(13) Mary wants to marry a rich man. He must be a banker.

${ }^{8}$ For my present expository purposes, I assume the standard account of the specific/non-specific ambiguity, in terms of a scope interaction between the indefinite NP and the modal verb, as an intuitive and descriptively adequate explanation. The formal analysis that I will put forward in Section 3.5, however, while maintaining that indefinites are interpreted as existential quantifiers in both specific and non-specific construals, keeps to a principle of interpretation in situ, even in cases of specific interpretation (Reinhart 1997; Kratzer 1998; Schwarzschild 2002).

997; Kratzer 1998; Schwarzschild 2002).
9 Pretty much in the same way as the semantics of the Priorian tense operators $\mathrm{P}$ and $\mathrm{F}$ is given in firstorder temporal logic. See Kissine (2008a) for a proposal in which the future auxiliary will is analysed as a I'tiorian tense operator.

10. Karttunen makes the observation in question in footnote 3 of Karttunen (1976):

What remains unexplained here is the fact (pointed out to me by John Olney) that must in [(4a)] [Mary wants to marry a rich mam. He must be a banker] ] has two meanings depending on the specificity of the NP
a rich man in the preceding sentence. If the first sentence is about a specific man, then must in the second sentence is interpreted in a ratier weak sense 'It is likely that he is a banker'. But if the NP a rich man is nonspecific, the second sentence means. 'It is necessary that he be a banker' 
His observation about (13) is two-fold:

(a) The specific reading of a rich man in the left sentence of the sequence naturally correlates with the epistemic reading of must in the right sentence, paraphrasable as 'It is likely that he is a banker'.

(b) The non-specific reading of the indefinite naturally correlates with a teleological reading of the modal, along the lines of the paraphrase 'It is required that he be a banker.'11

In support of Karttunen's observation, we can adduce a couple of considerations. First, on its specific interpretation, the indefinite a rich man introduces a particular discourse referent $x$ which provides a suitable target for the subsequent guess: that ver $y$ must be a banker; crucially, it would not make sense to make a guess of this form if the variable $x$ were not anchored to a particular previously established referent. Second, on its non-specific interpretation, the indefinite a rich man can antecede the definite pronoun he only if the latter is in the semantic scope of must-indeed, a non-modal continuation like She saw him at the opera would not be acceptable, while a one-anaphora would be needed in such context, for example She saw one at the opera; on this scope construal of the continuation, the modal must is naturally understood as elaborating on Mary's bouletic worlds: intuitively, it brings in a further condition that has to be satisfied in each one of those worlds.

A criticism which is worth addressing at this preliminary stage, to pave the way to the argument that I will develop later on, is the possibility of contexts in which $a$ rich man is specific and must is nevertheless teleological. One such type of context is characterized by the fact that the source of the teleological modal base of must is not Mary, that is, it is not Mary who imposes the requirements that a man must meet in order to be eligible to become her husband. ${ }^{12}$ Suppose that you are the teleological source in question, and among the requisites that the future husband of Mary has to satisfy, you contemplate the property of being a banker. Suppose further that you have overheard that there is a certain wealthy fellow whom Mary wants to marry. In this case, you could say (14) to me:

(14) I heard that Mary wants to marry a rich man. You should remind her that he must be a banker!

At least if embedded in a discourse like (14), which favours the dissociation between Mary and the modal source, (13) does allow for the combination of a specific

11 The terminology adopted here is based on Portner (2009), who distinguishes deontic modality from teleological modality as two different sub-types of what he calls priority modals (Portner 2009: 135). On the one hand, deontic modals are based on moral concepts such as obligation, right, and wrong. On the other.

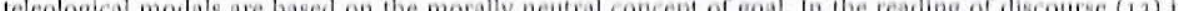
which must expresses a requirement, clearly there is no moral concept involved, but only a goal.

12. Thastes to an anonymous reviewer for pointing this out to me
. interpretation of a rich man and a teleological interpretation of must. ${ }^{13}$ We will thus take the possibility of this context into account in restating Karttunen's observation in the form of a stricter generalization, along the following lines:

(15) Karttunen's Generalization

In a discourse of the form NP wants to $\mathrm{V}\left[\mathrm{a} \mathrm{N}^{\prime}\right]_{i} . \mathrm{He}_{i} / \mathrm{She}_{i}$ must be $\mathrm{P}$

a. The epistemic interpretation of must requires the specific interpretation of $\left[\mathrm{a} \mathrm{N} \mathrm{N}^{\prime}\right]$.

b. The teleological interpretation of must requires that [a $\left.\mathrm{N}^{\prime}\right]$ be non-specific (provided that the denotation of NP is the relevant teleological source).

In what follows, I will restrict the interpretation of my target discourses exclusively to contexts satisfying the proviso in (15b), and I will disregard contexts such as the one backgrounding (14). I will describe the interpretation of a Karttunen-type discourse as (i) modally independent, when it is characterized by a specific indefinite followed by an epistemic modal, or as (ii) an instance of modal subordination, otherwise. Consider (13), for example: on the one hand, the interpretation paraphrased as 'Mary wants to marry a rich man. As far as I know, he is a banker.' will be described as modally independent, since the modal base of must in this case is anchored to an external source (plausibly, the speaker's information state) and is independent from the bouletic modal base of want; on the other hand, the interpretation rendered as 'Mary wants to marry a rich man. To be eligible to become her husband, the man is required by Mary to be a banker.' will be described as an instance of modal subordination, since the modal base of must, intuitively, is dependent on the preceding bouletic modal base.

Let's now look at how the future will patterns in discourses similar to (13) above. First, consider the following minimal variant of (13):

(16) Mary will marry a rich man. He must be a banker.

It seems that the only possible reading of (16) is one in which a rich man is specific and must is epistemic (e.g. Mary will marry a certain rich man. As far as I know, he

${ }^{13}$ It still seems to me that, in the sentence You should remind her that he must be a banker! from discourse (14), the definite pronoun he must have some sort of indeterminate or generic referent, in spite of its indefinite antecedent a rich man being interpretable specifically in this context. To be sure, the variant of (14) given in (i) would be odd:

(1) I heard that Mary wants to marry Bill. You should remind her that Bill must be a banker!

the sort of generic interpretation of the definite pronoun he that I suppose to characterize (14) could be a phenomenon similar to the interpretation of you in (ii)

(ii) To get that job, you must have an expertise in formal semantics

Ilere, the pronoun you doesn't seem to work as a device to refer to the particular addressec of the utterance, but rather as a variable that gets universally quantified, as in the semi-formal paraphrase 'for all $x$, for $x$ to get that job, $x$ must have an expertise in formal nemantics. 
is a banker.), while a reading in which must is teleological does not seem possible. This is as we would expect, given the negative conclusion we drew from Stalnaker's Asymmetry. ${ }^{14}$

If in (16) we replace must with will have to, however, something interesting emerges:

(17) Mary will marry a rich man. He will have to be a banker.

For the variant (17), we do get the teleological interpretation that the rich man Mary will marry, whoever he will be, is required by her to be a banker. ${ }^{15}$ My intuition about (17) is that the teleological modality, as in Karttunen's original example, is associated with a non-specific interpretation of a rich man, and that if we forced specificity of the object (e.g. by using a definite NP instead), we would obtain a different interpretation for the whole discourse, as illustrated by (18):

(18) Mary will marry the rich man over there. He will have to be a banker.

While this discourse is probably interpretable in some way, whatever is the interpretation that we obtain for it, it does not seem to have a reading in common with (17).

Before considering further data with different necessity modals, it is worth noting that, even though (16) lacks a reading in which must is teleological, we would go too far if we claimed that a sequence will + must in a Karttunen-type discourse never displays the teleological interpretation of must. Consider the web-based discourses (19a,b) (the former is reported with its preceding context):

(19) a. [I'm looking to bid farewell to my trusty 1997 Audi A4 2.6 Estate which has $200,000 \mathrm{~km}$ on the clock. I'm looking for something just as solid and the same size but with much better fuel economy.] I will be buying a used car and it must be under $£ 6,000$.

b. When your EP comes out, I will buy a copy. It must be autographed though!

These examples seem to unambiguously express the teleological reading of must that was missing from (16), and, correspondingly, to feature a non-specific interpretation of the indefinite object: (19a)'s intuitive meaning is that the speaker plans to buy a used car and puts the requirement of costing less than 6,000 pounds on whatever car he will buy; in a parallel way, the intuitive meaning of $(19 \mathrm{~b})$ is that the speaker plans to buy a copy of the addressee's extended-play and puts the requirement of being autographed on the copy he will buy, whatever that will be.

14 The conclusion was: the future will does not license non-specific indefinties

15 Thanks to Bridget Copley for bringing my attention to this example (p.c). Note that discourse (17) doesn't have an eptstemic interpretation for the second sentence - the sentence cannot mean 'it is likely that the rich man she will marry is a banker' What uniquely matters here, howeves, is the possibility of the teleological reading
Other data bearing on the possibility of non-specific indefinites in will-sentences are Karttunen-type discourses in which the modal should occurs instead of must. Consider first the following constructed example: ${ }^{16}$

(20) Mary will marry a rich man. He should be a banker.

The modal should here is naturally interpreted as introducing a preference of Mary's on the candidates that she would positively consider for marriage, with an associated nonspecific interpretation of the indefinite-whatever rich man she will end up marrying, she has a preference for him to be a banker. It thus appears that a continuation with should gives rise to the 'non-specific indefinite + teleological modal' reading more easily than a continuation with must.

The fact just noted might well depend on a lexical difference between must and should with respect to their ability to undergo modal subordination, and this in turn might be related to a lexical difference between the two with respect to their temporal properties. Indeed, must seems to be more constrained than should in allowing for temporal shifts towards the future with stative complements, ${ }^{17}$ as shown by the contrast between (21a) and (21b):

(21) a. John will arrive at $3 \mathrm{pm}$. I should be at home then.

b. John will arrive at $3 \mathrm{pm}$. I must be at home then.

Only the former seems to allow for a relation of temporal anaphora between the willsentence and the should-sentence. The issue under discussion, however, would require a separate empirical investigation to be settled. Such an inquiry would go far beyond the scope of this chapter, and I will not have anything more to say about this in what follows.

Some web-based examples of will + should which show the possibility of a 'nonspecific indefinite + teleological modal' reading are reported in (22):

(22) a. You will probably only buy a safe once in your life. It should therefore be the best and most secure available.

b. The Director of Policy and Research will hire and supervise a Policy and Research Associate. S/he should be comfortable working in a small team

16 The interesting fact about should is that, like must, and unlike will have to, it allows for both epistemic and root (e.g. deontic and teleological) readings. Thanks to Nicholas Asher for bringing to my attention the fict that should seems to be more prone to elaborate on a preceding will-sentence than must (p.c.).

17 Portner (2009: 235) makes a similar observation, but he limits his claim to epistemic must, which he ontrasts with epistemic may. His own example of the contrast is (i) versus (ii) (his own [300a,b]), but we can add (iii) to his pattern to show the contrasting temporal behaviour of should, analogous to may in this can add

(i) Hohn must be happy when he gets here tomorrow

(ii) Joln may be happy when he gets here fomorow

(iii) John should be happy when lie gets here tomorrow 
environment and partnering with staff members with varying experience and levels.

c. The commanding Officer of Troops will appoint a mess officer for the troops. He should report to the Executive Officer of the ship any irregularities which may arise.

In intuitive terms, a common trait of the will-sentences in (22a)-(22c) is that they introduce some generic profile through their indefinite objects, which is then constrained by the subsequent should-sentence. ${ }^{18}$ The intuition here is that the indefinite objects in these examples are not specific at all-hence, they are non-specific indefinites.

Let me conclude the present section by summarizing the main outcomes. The claim that the indefinite object of an extensional verb in a will-sentence is necessarily specific would now appear to be problematic, in view of the crucial examples with must and should considered above. Apparently, we can make sense of the idea that will licenses non-specific indefinites in certain contexts, and we could be tempted at this point to propose a modal analysis of will. The problem with such an analysis is that it would still have to explain why Stalnaker's Asymmetry arises. I'll return to this dilemma at the end of the next section and again in Section 3.5, where a formal framework will be proposed in which a solution to the problem can be cast. In the next section, I'll start addressing an objection against the claim that, in Karttunen-type discourses, the teleological interpretation of the necessity modal requires the indefinite antecedent to be non-specific.

\subsection{NON-SPECIFIC INDEFINITE OR IGNORANCE OF THE REFERENT'S IDENTITY?}

As we saw in the previous section, discourse (20) ('Mary will marry a rich man. $\mathrm{He}$ should be a banker.') has a reading which points to the existence of non-specific interpretations of indefinites in will-sentences. I will now consider an argument to the effect that the interpretation of a rich man in (20) would only have a superficial resemblance to the genuine non-specific interpretation of indefinite objects in the complement of want. ${ }^{19}$ The argument, which ultimately will take us back to Stalnaker's Asymmetry, is as follows.

${ }^{18}$ As an anonymous reviewer has pointed out to me, discourses (22b) and (22c) involve will-sentences that are not interpreted as predictions, but as teleological statements themselves; for example, the willsentence in (22b) could be paraphrased as "The Director of Policy and Research is required to hire and cilperve a Polcy a on-specitic indectinte objects in will-sentencel

The argument has been presented to me by sandro Zuchi (p.e)
Consider dialogue (23):

(23) Bill: John will marry an Italian.

Jane: Who is she?

Bill: ??No one in particular / He doesn't know yet. She should be from Tuscany, though (as he would very much like to go live there).

Bill's reply to Jane's question clearly shows the teleological interpretation of should. Importantly, it also shows that the answer No one in particular is unacceptable, while the statement of ignorance He doesn't know yet is good. This is in striking contrast with the variant of (23) given in (24), in which want occurs instead of will. Both answers make full sense here:

(24) Bill: John wants to marry an Italian.

Jane: Who is she?

Bill: No one in particular / He doesn't know yet. She should be from Tuscany, though (as he would very much like to go live there).

Taking the unacceptability of No one in particular in (23) at face value, the objection is that there would be no genuine non-specific interpretation of the indefinite an Italian in this dialogue, but only ignorance on the part of the conversational participants (mainly on the part of John) with regard to the identity of the actual referent; relatcdly, the teleological interpretation of should in (23) would be made possible precisely by the fact that the identity of the referent is not known, not by the fact that there is no particular woman semantically related to the indefinite (there has to be such particular woman-so the argument runs, otherwise we would not understand why the answer No one in particular is bad).

I would like to suggest that there is more than ignorance of the woman's identity involved in (23). Provided that people normally decide themselves in advance on who they are going to marry, the fact that John does not yet know which Italian he will marry can be claimed to make objectively indeterminate which woman that will be, that is, to make it the case that there actually is no particular woman $x$ of whom it is true that John will marry $x$. So, it would remain that the indefinite is non-specific in (23).

Assuming that the indefinite is non-specific in (23), exactly as in (24), what must be explained is why the answer No one in particular is good in the latter dialogue but odd in the former. Here I'll put forward a suggestion, to be formally developed in the following section. Assuming that the answer No one in particular abbreviates John won't marry any particular Italian in (23) and John doesn't want to marry any particular Italian in (24), respectively, the contrast between the two dialogues corresponds to the contrast between the contradictory (25a) and the consistent (25b): 
(25) a. ??John will marry an Italian, but he won't marry any particular Italian.

b. John wants to marry an Italian, but he doesn't want to marry any particular Italian.

The formulation in (25a) makes it clear that the problem with the answer No one in particular in (23) is actually determined by a logical contradiction: that answer directly denies what has been previously asserted by uttering John will marry an Italian. Intuitively, if it is true that John will marry an Italian, then it is true that he will marry some particular Italian. On the other hand, it can be true that John wants to marry an Italian, without it being true that he wants to marry some particular Italian.

However-and here we come to the core of my suggestion, we cannot conclude from these observations that an Italian is specific in (25a), since we have not yet excluded the possibility that an indefinite in a will-sentence would be in the scope of a modal quantifier that, unlike the modal quantifier underlying want, would for some reason be bound to take maximum scope. According to this possibility, there would be a modal quantifier $\forall$ underlying each one of the two will-sentences in (25a), and this hypothetical quantifier would take scope over the positive indefinite an Italian and, crucially, over the negative indefinite (not) any particular Italian as well, that is, (25a) would be formally represented as the conjunction of two statements of the form $\forall \alpha \exists \beta X$ and $\forall \alpha \neg \exists \beta X$, which, assuming that the domain of $\forall \alpha$ is not empty, logically contradict each other. On the other hand, the modal quantifier lexically provided by want in (25b) would be able to take narrow scope with respect to other scope-bearing elements, so that the non-contradictory conjunction of two statements of the form $\forall \alpha \exists \beta X$ and $\neg \exists \beta \forall \alpha$ X would be a possible formal representation of (25b).

The core of my proposal is precisely that the possibility just highlighted is in fact realized. In the next section I will cast my proposal in a formal framework and show how the proposed analysis applies to the main data considered above.

\subsection{FORMALIZATION OF THE PROPOSAL}

To anticipate the main lines, I am going to propose that will-sentences, though not being modal in the same sense as sentences with must, still involve a universal quantification over a domain of modal alternatives: the domain of possible futures that are open at the time of utterance (Prior 1967; Thomason 1984). This universal quantification is due to a supervaluational strategy aimed at achieving the truth-conditional assessment of the will-sentence in spite of the plurality of possible futures that are all legitimate candidates for the world of evaluation. I already stress that the universal quantification is not part of the basic semantics of will, which on my analysis is treated as an extensional tense marker, and it cannot enter into scope interactions with other scope-bearing elements occurring in the sentence, unlike the quantification lexically triggered by must and similar modal verbs.

\subsubsection{THE SEMANTIC FRAMEWORK}

\subsubsection{The model and the semantic metalanguage}

I cast the analysis in a semantic framework called Partial Branching Time (PBT) in Del Prete (2013). A PBT-model is built on a domain of Kratzerian situations (Kratzer 1989): maximal moments of classic Branching Time ${ }_{1}{ }^{20}$ that is, instantaneous events maximally extended through space, are replaced by partial situations as basic elements which are partially ordered by the relation of temporal precedence. The central idea of Branching Time is extended to PBT: every situation comes with a unique past but many possible futures. Formally, this means that the relation of temporal precedence $\leq_{s}$ will not be a linear order on the domain of situations, but a partial order generating tree structures. Given any two situations $s_{1}, s_{2}$, the interpretation of the relational statement $s_{1} \leq_{s} s_{2}$ is that $s 1$ did occur from the perspective of $s_{2}$, while $s_{2}$ might occur from the perspective of $s_{1}$ (Belnap 1992), the occurrence of $s_{2}$ being expected given some relevant facts in $s_{1}$ and in its past. World-histories are defined as maximal chains of situations. Given any two (world-)histories $h, h^{\prime}$, and given any situation $s$, the relational statement $h \approx_{s} h^{\prime}$ means that $h$ and $h^{\prime}$ are identical up to and including situation $s$ and diverge from $s$ onwards-in other terms, $h^{\prime}$ is a historical alternative to $h$ at $s .{ }^{21}$

I assume a type system containing the basic semantic types e (for individuals), $t$ (for truth values), $i$ (for situations), and $s$ (for world-histories). ${ }^{22}$ The letters $h, h_{1}, h_{2} \ldots$, $s, s_{1}, s_{2} \ldots$, and $x, y, x_{1}, y_{1} \ldots$ are used as variables over histories, situations, and individuals, respectively, $\mathrm{c}$ is a context of utterance, that is, a sequence of parameter values among which we find the time of utterance $c_{t}$, that is, a given situation containing the utterance event, and the circumstance of utterance $c_{w}$-in the cases of interest to us, as we will see, $c_{w}$ does not correspond to a single history in the PBT-model, but to a set of such histories. Two value-assignments are used: $f$ is a one-place function which assigns individuals to variables of type e, while $\mathrm{g}$ is a two-place function which assigns situations to variables of type $\mathbf{i}$ relative to a world-history: given variable $s_{\mathbf{i}}$ of type $\mathbf{i}$ and world-history $h, \mathrm{~g}\left(\mathrm{~s}_{i}, h\right)$ is a situation belonging to $h$. As in Heim and Kratzer (1998), the lambda-term $\lambda x: \phi . \psi$ represents a partial function $f$ which is defined for an object $x$ if and only if the domain condition $\phi$ is satisfied; if $f$ is defined for $x$, then the value it assigns to $x$ is whatever value is described by $\psi$. I introduce a notation that will enable us to represent the result of applying a partial function $f$ to an object $x$, while keeping track of the definedness condition of $f$ in the description of the output:

By classic Branching Time, I refer to the conception of BT which is proposed in Prior (1967) and Thomason (1984). The reader is referred to Belnap et al. (2001) for an in-depth investigation of BT-models and a proposal of semantic analysis of natural language constructions based on such models.

21 for a full-fledged presentation of a PBT-model, see Del Prete (2013).

22 Notice that this system does not contain a type for times, this is because, in the adopted model, situ ations play the same role as is played by time intervals in other systems 
if $\lambda x: \phi[x] . \psi[x]$ represents the partial function $f$, then the result of applying $f$ to an object denoted by a constant $a$ is described by the notation $\{\phi[a]\} \psi[a]$, whose intuitive meaning is that we get the value $\psi[a]$ provided that the domain condition $\phi[a]$ is satisfied.

The evaluation function $\llbracket \rrbracket$ is parameterized to a context $c$, assignment functions fand $\mathrm{g}$, and a world (circumstance of evaluation) $w$. When the circumstance $w$ is set up by the context,that is, $w$ is the circumstance of the context (or actual circumstance), we have the case of denotation in context, which, for sentential utterances, coincides with truth in context. Since we are only interested in truth in context here, the circumstance parameter $w$ in $\llbracket \rrbracket_{c, f, g, w}$ will always take the actual circumstance $c_{w}$ as its value. ${ }^{23} \mathrm{I}$ assume that contexts normally set up a determinate value for their parameters, for example the agent parameter is valuated as the particular author of the utterance, the time parameter as the particular time at which the utterance occurs, and so on.

\subsubsection{Openness of the world parameter}

As far as the world parameter is concerned, however, I assume that we face a lack of determinateness: due to the open character of the future state of the world, the context cannot set up a particular history as value for this parameter. Thus, the world parameter is an instance of open contextual parameter (Belnap et al. 2001; Bonomi and Del Prete 2008), that is, a contextual parameter that allows for any one of a plurality of equally legitimate valuations. In the following, I will technically implement the openness of the world parameter $c_{w}$ by having its value represented as the set of all the candidates for the future continuation of the present situation $c_{t}$, that is, the set of all histories $h$ in the PBT-model such that $c_{t} \in h$-these histories are identical up to and including the present situation $c_{t}$ and diverge only from some point after $c_{t}$. As far as the semantic evaluation of past tensed sentences is concerned, the openness of the world parameter does not pose any problem to us, given the backward-linear structure of the PBT-model. As we turn to the evaluation of a future tense sentence WILL( $p)$, however, the openness of the world parameter does raise a problem: in this case, we face a plurality of possible histories that are all legitimate candidates to represent the actual future state of the world, and we do not know a priori which one should be selected for the semantic evaluation of the prejacent proposition $p$. I will assume that the way out of this indeterminateness problem is a supervaluational strategy of universal quantification over the domain of possible histories ('Thomason 1984), whereby the temporal variable that on my analysis is introduced by will gets instantiated on every

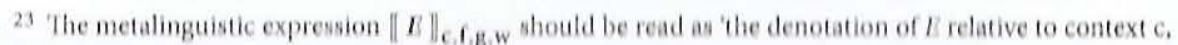
assignments f and $g$, and world $w^{\prime}$. In the following, I will freely skip reference to any evaluation parameters whenever they are not relevant for the semantic evaluation of a linguistic expression possible future. The default interpretation of a will-sentence will thus be a universal quantification over a domain of possible futures.

In the following subsections, I will provide the technical details of the semantic analysis of the main linguistic ingredients in our examples: verbal and nominal predicates, modal predicates, indefinite NPs and anaphoric definite pronouns, and, finally, the future auxiliary will -the main target of our inquiry.

\subsubsection{VERBAL AND NOMINAL PREDICATES}

I assume that verbal and nominal predicates alike introduce a situation argument into the semantic representation, besides the individual arguments that are predictable from their surface argument structures. Situation and individual arguments alike get locally bound by $\lambda$-operators in the usual way. This is shown in (26) for the transitive verb marry and in (27) for the noun woman:

(26) $\llbracket$ marry $\rrbracket=\lambda s . \lambda y \cdot \lambda x \cdot \operatorname{marry}(s, x, y)$

(27) $\llbracket$ woman $\rrbracket=\lambda s \cdot \lambda x \cdot \operatorname{woman}(s, x)$

Thus, the verb marry denotes a function which takes a situation $s$, an individual $y$ and another individual $x$ as arguments, and yields the value True if and only if $x$ marries $y$ in $s$, whereas the noun woman denotes a function which takes a situation $s$ and an individual $x$ as arguments and yields the value True if and only if $x$ is a woman in $s$.

\subsubsection{MODAL PREDICATES}

As in Kratzerian approaches to modality, I analyse both the epistemic and the teleological interpretation of must and should in terms of universal quantification over a domain of modal alternatives, where the difference between the two interpretations comes down to a difference in how the domain of quantification is defined. I will not make explicit reference to ordering sources, though, and I will instead use the simplilicd notation $\operatorname{ALT}_{\text {epistemic }}\left(w, w^{\prime}\right)$ (respectively, $\operatorname{ALT}_{\text {teleo }}\left(w, w^{\prime}\right)$ ) to mean that $w^{\prime}$ is an cpistemic (respectively, teleological) alternative to $w$ which is most compatible with certain relevant norms holding in $w$. The intensional verb want, which unlike modal auxiliaries expresses a propositional attitude of its subject, is also analysed in terms of universal quantification over modal alternatives, that is, the possible worlds in which the subject's desires are realized (or bouletic alternatives of the subject with respect to the actual world).

To account for the intuitive relation of modal dependence between must/should and want in Karttunen-type discourses like (13) (repeated below as (28)), I assume that must/should can quantify over a domain of possible worlds that they inherit from a preceding modal sentence. 
(28) Mary wants to marry a rich man. He must be a banker.

In the case of (28), want is interpreted relative to a modal base which is the set of Mary's bouletic alternatives to the actual world (in symbol, $\left.\left\{w: \operatorname{ALT}_{\text {boule }}\left(c_{w}, w, M a r y\right)\right\}\right)$, and the first sentence says that in every one of these worlds Mary marries somebody who is a rich man in that world. Then the subsequent modal must is interpreted relative to a modal base which in fact coincides with the preceding one: the second sentence says that every world $w$ which is one of Mary's bouletic alternatives to the actual world $c_{w}$ in which she marries a rich man (hence, every $w$ which is one of Mary's bouletic alternatives to $c_{w}$ tout court) is such that the rich man Mary marries in $w$ is a banker in $w$.

I do not assume that the future auxiliary will is to be treated on a par with modal predicates like want; accordingly, I will treat it in a separate subsection (Section 3.5.5).

\subsubsection{INDEFINITE NPS AND DISCOURSE-LEVEL DEFINITE PRONOUNS}

Indefinite NPs are assumed to semantically contribute existential quantification, as in standard Russellian treatments. More specifically, indefinites are Generalized Quantifiers over individuals (usual semantic type $<<e, t>, t>$ ). As such, they undergo Quantifier Raising (QR) at LF, leaving a coindexed trace behind which gets bound by a local $\lambda$-operator. By QR, an indefinite may end up being adjoined to a VP. On my analysis, VPs have semantic type $\langle i, t\rangle$, the type of properties of situations. This means that when $\mathrm{QR}$ targets an indefinite $\alpha$ in a structure $[\mathrm{VP} \ldots \alpha \ldots$, the resulting adjunction site $\lambda_{\mathrm{i}}\left[\mathrm{vP} \ldots t_{\mathrm{i}} \ldots\right]$ will end up having semantic type $<\mathrm{i},<\mathrm{e}, \mathrm{t} \gg>$, not $<\mathrm{e}, \mathrm{t}>$. For cases of this sort, I assume that the indefinite is shifted from its basic type $<<e, t>$, $t>$ to the type $<<\mathrm{i},<\mathrm{e}, \mathrm{t}>>,<\mathrm{i}, \mathrm{t} \gg>$. ${ }^{24}$ Unlike in standard Russellian treatments (e.g. Ludlow and Neale 1991), and following insights from 'choice-function' theorists (e.g. Reinhart 1997; Kratzer 1998), I assume that the representation of an indefinite NP at LF involves a variable over choice-functions ( $c$-functions, for short) which is carried by the indefinite determiner $a$, and can either be assigned a contextually salient function or be bound by an existential quantifier with free scope options relative to other scopebearing elements in the sentence. I follow Kratzer (1998) more closely in assuming that c-functions have variable adicity; in the cases of interest to us, a c-function $f$ will take two arguments, that is a property $P$ and a situation or possible world $s$, and will yield an individual $f(P, s)=x$ which has property $P$ in $s$. To give an example, the NP $a$ blond woman is interpreted as follows (the subscript ' $f$ ' on the indefinite determiner is the c-function variable provided by it):

\footnotetext{
${ }^{24}$ A type-shif of this kind is an instance of what is known as Geachs Rule in flexible categorial grammars.
}

(29) $\llbracket\left[\mathrm{a}_{f}\right.$ blond woman $\left.]\right]=\lambda \mathrm{P}<\mathrm{i},<\mathrm{e}, \mathrm{t}>>. \lambda \mathrm{s}_{\mathrm{j}} . \exists \mathrm{x}\left[f\right.$ (blond-woman, $\left.\mathrm{s}_{\mathrm{i}}\right)=\mathrm{x} \wedge$ $\left.\mathrm{P}\left(\mathrm{s}_{\mathrm{j}}, \mathrm{x}\right)\right]^{25}$

I further assume an e-type analysis of definite pronouns in discourse-level anaphoric relations, along the lines of Heim (1990) and Elbourne (2002). To show how all these assumptions work together in a particular case, consider discourse (30):

(30) John married a blond woman. She was twenty years old.

For the sake of simplicity, let's assume that the LF of (30) is as in (31), where the past tense morpheme -ed carries a referential index whose value must be a situation in the past, as in referential/presuppositional analyses of tense (Heim 1994).

(31) $\left[\mathrm{TP}-\mathrm{ed}_{0}\left[\mathrm{VP}[\mathrm{a} f \text { blond woman }]_{1} \lambda_{1}\left[\mathrm{VP}\right.\right.\right.$ John marry $\left.\left.\left.t_{1}\right]\right]\right]\left[\mathrm{TP}-\mathrm{ed}_{2}[\mathrm{VP}\right.$ she $_{1}$ be twenty years old]]

The semantic values of the LF-constituents [a $a_{f}$ blond woman ${ }_{1}, \lambda_{1}$ [vp John marry $t_{1}$ ], and she $e_{1}$ are given in (32a)- $(32 \mathrm{c})$ below, while the truth conditions of the whole discourse are given in (32d). Since the meaning of the second sentence in (30), intuitively, is that the relevant woman was 20 years old at the same time that John married her, I assume that the past tense morpheme $-\mathrm{ed}_{2}$ in the second sentence refers to the same situation as the past tense morpheme - $\mathbf{e d}_{\mathrm{o}}$ in the first sentence. Furthermore, I assume that the $c$-function variable $f$ carried by the indefinite determiner is assigned a contextually salient function $f_{\mathrm{c}}$ in this case.

(32) a. $\llbracket\left[\mathrm{a}_{f} \text { blond woman }\right]_{1} \rrbracket_{\mathrm{c}}=\lambda \mathrm{P}<\mathrm{i},<\mathrm{e}, \mathrm{t}>>, \lambda \mathrm{s}_{\mathrm{j}}, \exists \mathrm{x}\left[f_{\mathrm{c}}\left(\right.\right.$ blond-woman, $\left.\mathrm{s}_{\mathrm{i}}\right)=$ $\left.\mathrm{x} \wedge \mathrm{P}\left(\mathrm{s}_{\mathrm{j}}, \mathrm{x}\right)\right]$

b. $\left[\lambda_{1}\left[\right.\right.$ VP Johnmarry $\left.\left.t_{1}\right]\right]=\lambda s_{j}, \lambda x \cdot \operatorname{marry}\left(s_{j}\right.$, John, $\left.\mathrm{x}\right)$

c. $\left[\mathrm{she}_{1}\right]_{\mathrm{c}}=[\mathrm{ix}]\left[f_{\mathrm{c}}\right.$ (blond-woman, $\left.\left.\mathrm{s}_{\mathrm{i}}\right)=\mathrm{x}\right]$

d. [(30) $]_{c}=1$ iff $\exists \mathrm{x}\left\{\mathrm{s}_{\mathrm{o}}<\mathrm{s} c t\right\}\left[f_{\mathrm{c}}\left(\right.\right.$ blond-woman, $\left.\mathrm{s}_{\mathrm{o}}\right)=\mathrm{x} \wedge \operatorname{marry}\left(\mathrm{s}_{\mathrm{o}}\right.$, John, $\left.\left.\mathrm{x}\right)\right]$ $\wedge$ 2o-years-old $\left(\mathrm{s}_{\mathrm{o}},[\mathrm{tx}]\left[f_{\mathrm{c}}\left(\right.\right.\right.$ blond-woman, $\left.\left.\left.\mathrm{s}_{\mathrm{o}}\right)=\mathrm{x}\right]\right)$

The analysis correctly predicts that (30) is true if and only if there is a blond woman $x$, selected in the contextually relevant past situation $s$ by the contextually relevant procedure $f \mathrm{c}$, such that John marries $x$ in $s$ and $x$ is twenty years old in $s$.

The variables si, si can, but need not, refer to the same situation. 'The empirical motivation for this is us follows. In a sentence like $I$ saw a blonde, the most likely interpretation is that I saw a woman in a past situation $s^{4}$, and the woman was blond in that same situation $s^{4}$. On the other hand, the sentence $A$ friend of mine was born in Novosibirsk is most likely interpreted as saying that somebody who is a friend of mine in the present situation was born in Novosibirsk in some past situation. Therefore, we have reasons to preserve the possibility that the situation out of which the c-function selects an individual and the situation projected by the verb predicate do not coincide. 


\subsubsection{THE FUTURE AUXILIARY WILL}

I propose that will has the semantics of a tense marker: it introduces a temporal variable into the semantic representation, whose value is presupposed to be a situation in the future of the utterance situation. No quantification whatsoever over modal alternatives is semantically contributed by will. Hence, will is different from modal predicates like want, that, as we have seen in Section 3.5.3, do semantically contribute quantification over a domain of modal alternatives.

The lexical entry for will is given in (33) (the subscript ' $k$ ' on the tense marker is the temporal index that it bears at LF, which matches the situation variable ' $s_{k}$ ' in the semantic representation):

(33) $\llbracket$ will $_{k} \rrbracket_{\mathrm{c}, \mathrm{g}, \mathrm{h}}=\lambda \mathrm{P}<\mathrm{i}, \mathrm{t}>: \mathrm{c}_{t} \leq_{\mathrm{s}} \mathrm{g}\left(\mathrm{s}_{k}, \mathrm{~h}\right) . \mathrm{P}\left(\mathrm{g}\left(\mathrm{s}_{k}, \mathrm{~h}\right)\right)$

On this analysis, will takes a property of situations as argument and yields a truth value, provided that a certain condition is satisfied. The domain condition $c_{t} \leq \mathrm{s} g\left(s_{k}, h\right)$ in (33) is the presupposition triggered by will, according to which the value of the temporal variable ' $s_{k}$ ' has to be in the future of the utterance situation $c_{t}$ along the history of evaluation $h$.

To see how this analysis works on a concrete case, consider sentence (34), given along with its LF (35).

(34) John will marry a blond woman.

(35) $\left[\mathrm{TP}\right.$ will $_{k}\left[\mathrm{VP}_{3}[\mathrm{NP} \text { a blond woman }]_{1} \lambda_{1}\left[\mathrm{VP}_{2}\right.\right.$ John [VP 1 marry $\left.\left.\left.t_{1}\right]\right]\right]$

I will first make the simplifying assumption that the world parameter of the evaluation function $\| \rrbracket$ is set to a determinate world-history $h$. Given this assumption, the truth conditions of (34), relative to LF (35), are compositionally derived as follows (I also assume that the context of utterance provides a value for the $c$-function variable of the indefinite):

(36) $[$ John $]=$ John

$\llbracket \operatorname{marry} \rrbracket=\lambda s_{\mathrm{i}} \cdot \lambda \mathrm{y}_{\mathrm{e}} \cdot \lambda \mathrm{x}_{\mathrm{e}} \cdot \operatorname{marry}(\mathrm{s}, \mathrm{x}, \mathrm{y})$

$\left[\left[\mathrm{VP}_{1}\right.\right.$ marry $\left.\left.\left.t_{1}\right]\right]\right]_{\mathrm{c}, \mathrm{f}, h}=\lambda \mathrm{s} . \lambda \mathrm{x} \cdot \operatorname{marry}\left(\mathrm{s}, \mathrm{x}, \mathrm{f}\left(t_{1}\right)\right)$

[I $\left.\left[\mathrm{VP}_{2} \operatorname{John}\left[\mathrm{VP}_{1} \operatorname{marry} t_{1}\right]\right]\right]_{\mathrm{c}, \mathrm{f}, h}=\lambda \mathrm{s} . \operatorname{marry}\left(\mathrm{s}, \operatorname{John}, \mathrm{f}\left(t_{1}\right)\right)$

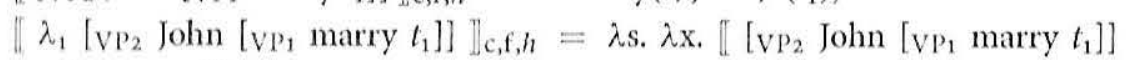
Hc, $f|1 / x|, h^{26}$

$\|$ a blond woman $\|_{c, f, h}=\lambda \mathrm{P}<\mathrm{i},\left\langle\mathrm{c}, \mathrm{t}>>. \lambda \mathrm{s} . \exists x\left[\int_{\mathrm{c}}\right.\right.$ (blond-woman, $\left.\mathrm{s}\right)=$ $x \wedge \mathrm{P}(\mathrm{s}, x)]$

$\|\left[\mathrm{VP}_{3}[\mathrm{NP} \text { a blond woman }]_{1} \lambda_{1}\left[\mathrm{VP}_{2}\right.\right.$ John $\left[\mathrm{VP}\right.$, marry $\left.\left.\left.t_{1}\right]\right]\right] \|_{c, f, h}=\lambda \mathrm{s} . \exists x$ $\left[\int_{c}(\right.$ blond-woman, $s)=x \wedge \operatorname{marry}(\mathrm{s}, J$ ohn, $x)$ ]

16. Where $\mathrm{n}$ is an individual variable and $i$ an individual, $f \mathrm{n} / \mathrm{n}$ is the value-asignment auch that, for any individual variable $m \times n_{1} f(n / I)(m)=\lceil(m)$, and $f(n / I)(n)=1$.
[[ $\left[\mathrm{TP}\right.$ will $_{k}\left[\mathrm{VP}_{3}[\mathrm{NP} \text { a blond woman }]_{1} \lambda_{1}\left[\mathrm{VP}_{2} \operatorname{John}\left[\mathrm{VP}_{1}\right.\right.\right.$ marry $\left.\left.\left.\left.\left.t_{1}\right]\right]\right]\right]\right]_{\mathrm{c}, \mathrm{g}, h}=1$ iff $\left\{c_{t} \leq_{S} \mathrm{~g}\left(s_{k}, h\right)\right\} \exists x\left[f_{\mathrm{c}}\left(\right.\right.$ blond-woman, $\left.\mathrm{g}\left(\mathrm{s}_{k}, h\right)\right)=x \wedge \operatorname{marry}\left(\mathrm{g}\left(\mathrm{s}_{k}, h\right)\right.$, John, $\left.\left.x\right)\right]$

Thus, on the assumption that the world parameter of the evaluation function is set to the particular history $h$, the analysis predicts that (34) is true if and only if there is a blond woman $x$, selected in the situation $\mathrm{g}\left(\mathrm{s}_{k}, h\right) \in h$ by the contextually relevant procedure $f_{\mathrm{c}}$, such that John marries $x$ in $\mathrm{g}\left(\mathrm{s}_{k}, h\right)$-provided that $\mathrm{g}\left(\mathrm{s}_{k}, h\right)$ follows the utterance situation $c_{t}$ along $h .^{27}$

This, however, is not the whole story about will-only the whole semantic story. Indeed, I have assumed in Section 3.5.1 that when a sentence WILL $(p)$ is uttered, normally the context of utterance does not set up a determinate history as the world of cvaluation, due to the openness of the future. Accordingly, the other part of the story about will is that it comes to have a modal potential which depends on the forward branching structure of the PBT-model. The whole range of histories passing through $c_{l}$ is relevant for the truth conditional evaluation, and in order to overcome the plurality of histories speakers resort to a supervaluational strategy requiring that the future tensed statement hold for any such history. To see how the analysis works in a concrete case, consider (34) again. The 'supervaluated' truth conditions are now given in (37) (as before, I assume that the context provides a value for the $c$-function variable):

(37) $\mathbb{U}\left[\mathrm{TP}\right.$ will $_{k}\left[\mathrm{VP}_{3}\left[\mathrm{NP} \text { a } \mathrm{f}_{f} \text { blond woman }\right]_{1} \lambda_{1}\left[\mathrm{VP}_{2}\right.\right.$ John $\left[\mathrm{VP}_{1}\right.$ marry $\left.\left.\left.\left.\left.t_{1}\right]\right]\right]\right]\right]_{\mathcal{c}, \mathrm{g}, \mathrm{c}_{w}}$ $=1$

iff $\forall h_{1}\left[h_{1} \approx_{c t} h_{0} \rightarrow\left\{c_{t} \leq \mathrm{s} g\left(s_{k}, h_{1}\right)\right\} \exists x\left[f_{\mathrm{c}}\right.\right.$ (blond-woman, $\left.\mathrm{g}\left(\mathrm{s}_{k}, h_{1}\right)\right)=x \wedge$ $\operatorname{marry}\left(\mathrm{g}\left(\mathrm{s}_{k}, h_{1}\right)\right.$, John, $\left.\left.\left.x\right)\right]\right]$

The analysis predicts that (34) is true, relative to the (open) actual circumstance $c_{w}$, if and only if for every history $h_{1}$ in $c_{w}$, there is a blond woman $x$, selected by the contextually relevant procedure $f_{\mathrm{c}}$ in the situation $\mathrm{g}\left(\mathrm{s}_{k}, h_{1}\right)$, such that John marries $x$ in $\mathrm{g}\left(\mathrm{s}_{k}\right.$, $h_{1}$ )-provided that $\mathrm{g}\left(\mathrm{s}_{k}, h_{1}\right)$ follows the utterance situation $c_{t}$ along $h_{1}$. Notice that, from these modalized truth conditions for (34), it follows that there may be different women married by John on different futures. This is precisely the upshot of the openness of the future: it may be indeterminate which woman John will marry.

The fictional assumption that I have made, to the effect that the world parameter of the evaluation finction is set to a particular history, seems to describe a situation that actually obtains in 'narrative' conIexts, in which the historical present is typically used, as in the following example taken from a Chronological Ilistory of Wyoming <http://www.shgresources.com/wy/timeline/>:

(1) 1941 - Richard Cheney is born in Lincoln, Nebraska, on January 3oth. He will grow up in Casper, Wyoming, and earn his bachelor's and master's of arts degrees from the University of Wyoming,

The purely temporal value of will appears clearly from examples of this type, where the narrated events are located in the past (in spite of being reported in the present lense) and the narrator has complete information about the relevant sequence of events. In examples of this sort there seems to be no plurality of possible futures involved in the evaluation of a will-sentence. 
Before moving to the next section, it is worth emphasizing that, on the analysis that I have proposed, universal quantification is not contributed by the semantics of will, but enters the picture through the (super)valuation of the global linguistic context in which will is embedded. The only contribution of will to the semantic representation is a temporal variable. Notice that a consequence of the supervaluational approach is the following: if the event reported by the future sentence occurs at some values of the temporal variable but not at others, the statement cannot be evaluated as true, since the event may fail to occur at the relevant time, nor can it be evaluated as false, since the event may occur then. ${ }^{28}$ This, I believe, correctly accounts for the intuition that genuine 'future contingents', such as the statement The die will come up six next timemade in a context in which the die is known to be fair, cannot possibly be evaluated as either true or false at the time they are uttered, while one has to wait for positive or negative future evidence in order to assess the utterance (see MacFarlane 2003, 2008).

\subsubsection{STALNAKER'S ASYMMETRY EXPLAINED}

Given that the universal quantification is not lexically contributed by will but comes from the supervaluational strategy aimed at evaluating the whole sentential utterance, one might wonder how the universal quantifier may scopally interact with the existential quantifier of the indefinite to generate the specific/non-specific ambiguity. In fact, I claim that there is no possible scope interaction between the two. This lack of scope interaction is far from being an obstacle to explaining specific construals. So much so

28 The same situation arises in natural language in other cases in which the evaluator faces a plurality of objects relevant to the semantic evaluation-for example, when sentences containing vague predicates are used. Consider the pair in (i):

(i) a. Mount Everest is a high mountain.

b. Gran Sasso is a high mountain.

No matter what standard of height for mountains we select, (i.a) is certain to wind up true; accordingly, we are inclined to evaluate it as true, regardless of what the context of the utterance is. The truth of (i.b), however, is contingent on what standard of height for mountains counts as the most relevant standard in the context; accordingly, if we face a plurality of potentially relevant standards, we may be unable to evaluate the sentence as true or false, insofar as the standards may differ significantly from one another and, consequently, the sentence may turn out to be true relative to some and false relative to others. The truth-status of (i.b) becomes clearer as soon as a definite standard of height is referred to, or a restricted truth-st of (i.b) bechestricte class of standards is isolated cin this case the sentence will be evaluated as true if it is true relative to the strictest standard in the class, hence relative to any standard therein. These considerations on the evaluation of sentences with vague predicates make it clear that the situation we face when we evaluate future sentences is not new: we have a plurality of entities that are equally relevant for the evaluation, and it would be arbitrary to select any one of such entities as the right input for the evaluation function. In both cases, the evaluators strategy is supervaluational: evaluate as true (or false) just in case the choice of the entity relevant to the evaluation does not make any difference in the resulting value.

An anonymous reviewer has suggested that the supervaluation works differently for a vague predicate like high and for a will-sentence in the former case, the context may provide a standard as to what counts as high, but no such provision would be available in the case of the future. I disagree with the reviewer in view of the data about narrative contexts referred to in footnote 29 that I will propose that there are no scope interactions between the indefinite and the modal in lexically modal sentences either (e.g. Mary wants to marry a rich man).

The explanation of the specific/non-specific ambiguity in terms of scope ambiguity, which I have temporarily assumed in Section 3.2 , is not the only available option, and not even the most plausible one from the point of view of a principled theory of the syntax-semantics interface, as many scholars have emphasized (Reinhart 1997; Kratzer 1998; Schwarzschild 2002; to cite only a few). Here, I will show how the analysis of indefinites that I have delineated in Section 3.5.4, together with the other semantic assumptions from the previous sections, can account for specific indefinites in modal and will-sentences, without the need to assign the existential quantifier of the indefinite wide scope relative to the modal quantifier.

Consider sentences (38) and (39) below. Assuming that the situation argument of the choice function is instantiated to the actual world $c_{w}$ in both cases, my analysis predicts the truth conditions given in $\left(38^{\prime}\right)$ and $\left(39^{\prime}\right)$ :

(38) John will marry an Italian woman.

(38') $\forall h_{1}\left[h_{1} \approx c_{t} h_{0} \rightarrow\left\{c_{t} \leq s \mathrm{~g}\left(\mathrm{~s}_{k}, h_{1}\right)\right\} \exists \mathrm{x}\left[f_{\mathrm{c}}\left(\right.\right.\right.$ Italian-woman, $\left.\mathrm{c}_{w}\right)=\mathrm{x} \wedge$ marry $\left.\left.\left(\mathrm{g}\left(\mathrm{s}_{k}, h_{1}\right), \mathrm{John}, \mathrm{x}\right)\right]\right]$

(There is an Italian woman $x$, uniquely identified in the actual world by the contextually relevant procedure $f_{\mathrm{c}}$, such that, for every possible future $h$, John marries $x$ on $h$.)

(39) John wants to marry an Italian woman.

(39') $\forall w_{1}\left[\operatorname{ALT}_{\text {boule }}\left(\mathrm{c}_{w}, w_{1}, \mathrm{John}\right) \rightarrow \exists \mathrm{x}\left[f_{\mathrm{c}}\left(\right.\right.\right.$ Italian-woman, $\left.\mathrm{c}_{w}\right)=\mathrm{x} \wedge \operatorname{marry}\left(w_{1}\right.$, John, $\mathrm{x})]]$

('There is an Italian woman $x$, uniquely identified in the actual world by the contextually relevant procedure $f_{c}$, such that, for every bouletic alternative of John's $w$, John marries $x$ in $w$.)

Both truth conditions make it clear that the Italian woman selected by the c-function of the indefinite is independent from the modal alternative universally quantified over (be it a possible future, as in $\left(38^{\prime}\right)$, or a bouletic alternative of John's, as in $\left(39^{\prime}\right)$ ), since the woman is uniquely identified relative to the actual circumstance by the c.function. ${ }^{29}$

(9) Note that the actual world $c_{W}$ in $\left(38^{\prime}\right)$ encompasses all the historical alternatives in the domain of the univernal quantifier $V h_{1}$, according to my conception of the openness of the world parameter in PBT; thus, in (ait) the actual world $c_{w}$ is related to those historical alternatives in a way in which it is not related to John's bouletic alternatives in (39') - John's bouletic alternatives are not part of $c_{W}$ as the historical alternatives at $G$ are In spite of this relationship between $c_{W}$ and the world-histories quantified over in $\left(38^{\prime}\right)$, the point remains that the cholce of the particular Italian woman fc(talian, $\left.c_{W}\right)$ is independent from the particular work - history $h$ selected to instantiate the univeral quantifier $V / h_{1}$, that is to say, the selected woman does not 60 -vary with the world history. 
I can now proceed to account for the data at the basis of Stalnaker's Asymmetry, namely the contrast between (40) and (41) below. As I said in Section 3.5.4, my analysis allows for the possibility that the c-function variable carried by the indefinite determiner be bound by an existential quantifier with free scope options relative to other scope-bearing elements. This possibility comes about whenever the context does not provide a value for the $\mathrm{c}$-function variable. I suggest that the phrase no one in particular, as occurring in (40) and (41), signals that the context of utterance does not set up a c-function which uniquely identifies an individual from the actual circumstance. Therefore, (40) and (41) are cases in which existential closure of the $c$-function variable is called for. Crucial for the explanation of the contrast between the two sentences is my assumption that the universal quantification underlying the will-sentence, unlike the one lexically triggered by want, is bound to have maximum scope: in particular, it cannot take narrow scope relative to negation in (41), nor can it take narrow scope relative to the existential closure of the $c$-function variable.

Given all this, the truth conditions that are derived on my analysis for (40) and (41) are $\left(40^{\prime}\right)$ and $\left(41^{\prime}\right)$, respectively. ${ }^{30}$

(40) John wants to marry an Italian, but no one in particular.

$\left(40^{\prime}\right) \exists f \forall w_{1}\left[\operatorname{ALT}_{\text {boule }}\left(\mathrm{c}_{w}, w_{1}\right.\right.$, John $) \rightarrow \exists \mathrm{x}\left[f\left(\operatorname{Italian}, w_{1}\right)=\mathrm{x} \wedge \operatorname{marry}\left(w_{1}, \operatorname{John}\right.\right.$, $\mathrm{x})]] \wedge \neg \exists f \forall w_{1}\left[\operatorname{ALT}_{\text {boule }}\left(\mathrm{c}_{w}, w_{1}, \mathrm{John}\right) \rightarrow \exists \mathrm{x}\left[f\left(\right.\right.\right.$ Italian, $\left.\mathrm{c}_{w}\right)=\mathrm{x} \wedge \operatorname{marry}\left(w_{1}\right.$, John, $\mathrm{x})]]$

(41) ??John will marry an Italian, but no one in particular.

(41') $\forall h_{1}\left[h_{1} \approx c_{t} h_{0} \rightarrow \exists f \exists \mathrm{x}\left[f\left(\right.\right.\right.$ Italian, $\left.\left.\left.h_{1}\right)=\mathrm{x} \wedge \operatorname{marry}\left(\mathrm{g}\left(\mathrm{s}_{k}, h_{1}\right), \mathrm{John}, \mathrm{x}\right)\right]\right] \wedge \forall h_{1}$ $\left[h_{1} \approx c_{t} h_{0} \rightarrow \neg \exists f \exists \mathrm{x}\left[f\left(\operatorname{Italian}, c_{w}\right)=\mathrm{x} \wedge \operatorname{marry}\left(\mathrm{g}\left(\mathrm{s}_{k}, h_{1}\right), \mathrm{John}, \mathrm{x}\right)\right]\right]$

On the one hand, sentence (40) is predicted to be true if and only if there is some way $f$ to select Italian women relative to bouletic alternatives of John's such that, for every such alternative $w$, John marries the woman selected by $f$ in $w$, but there is no way to select a particular Italian woman $x$ in the actual world $c_{w}$ such that, for every one of John's bouletic alternatives $w$, John marries precisely $x$ in $w$. These truth conditions are coherent and correspond to the intuitive meaning of (40). On the other hand, the truth conditions in (41') say that for every possible future $h$, there is some way $f$ to select an Italian woman $x$ in $h$ such that John marries $x$ in $h$, and for every possible future $h$, there is no way $f$ to select a particular Italian woman $x$ in the actual world $c_{w}$ such that John marries precisely $x$ in $h$. These truth conditions are incoherent: recall that the actual world $c_{w}$ is made up exactly of those world-histories $h$ which are open possibilities at the time of utterance $c_{l}$, namely the histories which are universally quantified in ( $\left.41^{\prime}\right)$,

30 To simplify the logical formula representing (41)'s truth conditions, I skip the part $\left|c_{1} \leq n g\left(s_{k}, h_{1}\right)\right|$ corresponding to the presuppositional requirement of will that its temporal variable be instantiated in the future.
Therefore (41') expresses the unsatisfiable requirement that on every possible future it be both possible to find an Italian woman married by John and impossible to find such a woman.

We have finally attained an explanation of why (41) sounds incoherent, unlike (40). Given that the contrast between (40) and (41) has been shown to be at the basis of Stalnaker's Asymmetry, we have by the same token explained the asymmetry in question.

\subsubsection{ANALYSIS OF KARTTUNEN-TYPE DISCOURSES}

When the discourses $(42 a, b)$ below obtain the 'non-specific indefinite + teleological modal' reading described in Section 3.3, they provide instances of modal subordinaIion (as argued for in Section 3.3). In this case, the definite pronoun he is interpreted in the scope of should and fails to refer to an individual salient in the discourse-context.

(12) a. Mary will marry a rich $\operatorname{man}_{i}, \mathrm{He}_{i}$ should be a banker.

b. Mary wants to marry a rich $\operatorname{man}_{i}$. $\mathrm{He}_{i}$ should be a banker.

I propose that in discourse (42a), under the modal subordination reading, the interprctation of should is dependent on the modal quantification over possible futures underlying the interpretation of the will-sentence, in a similar way as the interpretation of the same modal is dependent on the modal quantification lexically triggered by want in $(42 \mathrm{~b})$. The dependence of the interpretation of a modal on a preceding modal context is to be understood as I have proposed in Section 3.5.3: the modal should in (42a) quantifies over a modal base which coincides with the domain of the preceding universal quantifier over historical alternatives, that is to say, the domain of ihould is exactly the set of histories which are open possibilities at the time of utterance 4 (in symbols, $\left\{h: c_{t} \in h\right\}$ ), and the should-sentence introduces an additional condilion on cach alternative $h$ in this domain (on top of the condition introduced by the will-sentence, to the effect that Mary marries a rich man in $h$ ); intuitively, the shouldientence requires that any such historical alternative match some relevant norms originating from Mary.

I ct us turn for a moment to (42b). In this case, intuitively, the rich man married by Mary in her bouletic worlds has to be a banker according to Mary's relevant standards of cligibility - the standards that any man has to meet in order to be eligible to become Mary's husband. Thus, the meaning of the whole discourse (42b) could be paraphrased an 'Tich $w$ which is one of Mary's bouletic alternatives is such that Mary marries a fich man in $w$, and cach one of such alternatives $w$ that is also most compatible with Mary's standards of eligibility is such that the rich man married by Mary in $w$ is a banker in $w^{\prime}$.

Now, in the case of (42a), the relevant norms to which the interpretation of should refers are not fixed as easily as in the case of ( $42 \mathrm{~b})$, plausibly because the tense marker 
will, unlike the full modal verb want, is devoid of lexical meaning, therefore it is less clear to what propositional attitude of Mary the relevant norms presupposed by should are related. It seems plausible to assume that, in (42a), the relevant norms are more sensitive to the context than in (42b): they could be related to Mary's bouletic attitude, but they need not be.

Before proposing a formal analysis of the modal subordination reading of (42a), let us consider its modally independent reading, that is, the one in which the indefinite is specific and should epistemic. The truth-conditions corresponding to this reading of (42a) are computed on the basis of the LF (43) and are expressed in (44):

(43) $\left[\mathrm{TP}\right.$ will $k\left[\mathrm{VP}_{3}[\mathrm{NP} \text { a rich man }]_{1} \lambda_{1}\left[\mathrm{VP}_{2}\right.\right.$ Mary [vP $\left.\left.\left.\left.\mathrm{VParry}_{1}\right]\right]\right]\right]$ [ModP should [vP $h_{1}$ be a banker]]

(44) $\llbracket(40) \rrbracket_{c, g, c_{w}}=1$ iff

iff $\forall h_{1}\left[h_{1} \approx_{c t} h_{0} \rightarrow\left\{c_{t} \leq s \mathrm{~g}\left(s_{k}, h_{1}\right)\right\} \exists x\left[f_{\mathrm{c}}\right.\right.$ (rich-man, $\left.\mathrm{c}_{w}\right)=x \wedge \operatorname{marry}\left(\mathrm{g}\left(\mathrm{s}_{k}\right.\right.$, $\left.h_{1}\right)$, Mary, $\left.\left.\left.x\right)\right]\right] \wedge \forall w_{1}\left[\operatorname{ALT}_{\text {epistemic }}\left(c_{w}, w_{1}\right) \rightarrow \operatorname{banker}\left(w_{1},\left[\llcorner x]\left[f_{\mathrm{c}}(\right.\right.\right.\right.$ rich-man, $\left.\left.\left.\left.c_{w}\right)=x\right]\right)\right]$

The analysis predicts that discourse (42a) is true under the modally independent reading if and only if for every possible future $h$, there is a rich man $x$ which is uniquely identified in the actual world such that Mary marries $x$ in $\mathrm{g}\left(\mathrm{s}_{k}, h\right)$, and every possible world $w$ which is epistemically accessible from the actual world is such that the particular rich man $x$ is a banker in $w$. Notice that the definite description $\left[\llcorner x]\left[f_{\mathrm{c}}\right.\right.$ (rich-man, $\left.c_{w}\right)=x$ ] does not contain any occurrence of the variable ' $w_{1}$ ' bound by the universal quantifier ' $\forall w_{1}$ ' and picks up the same value as the choice function $f_{\mathrm{c}}$, that is, the same rich man across different epistemic alternatives, and that rich man is said to be a banker on every epistemic alternative. This seems to be intuitively correct.

Turning to the modal subordination reading of (42a), the corresponding truthconditions are given in (45):

(45) $\llbracket(42 a)]_{c, g, c_{1 v}}=1$ iff

iff $\forall h_{1}\left[h_{1} \approx_{c t} h_{0} \rightarrow\left\{c_{t} \leq s \mathrm{~g}\left(s_{k}, h_{1}\right)\right\} \exists x\left[f\left(\right.\right.\right.$ rich-man, $\left.h_{1}\right)=x \wedge \operatorname{marry}\left(\mathrm{g}\left(\mathrm{s}_{k}\right)\right.$ $\left.h_{1}\right)$, Mary, $\left.\left.\left.x\right)\right]\right] \wedge \forall h_{1}\left[\left(h_{1} \approx_{c_{t}} h_{\circ} \wedge \operatorname{ALT}_{\text {teleo }}\left(c_{w}, h_{1}\right)\right) \rightarrow \operatorname{banker}\left(\mathrm{g}\left(\mathrm{s}_{k}, h_{1}\right),[\iota x]\right.\right.$ $\left[f\left(\right.\right.$ rich-man, $\left.\left.\left.\left.h_{1}\right)=x\right]\right)\right]$

The analysis predicts that discourse (42a) is true under the relevant reading if and only if for every possible future $h$, there is some rich man $x$ which is selected in $h$ by the procedure $f$, such that Mary marries $x \operatorname{in} g\left(s_{k}, h\right)$, and if $h$ is also most compatible with some relevant norms holding in the actual circumstance, the rich man $x$ is a banker in $\mathrm{g}\left(\mathrm{s}_{k}, h\right)$. Notice that, in contrast with the truth conditions for the modally independent reading of $(42 a)$, the definite description $[t x]\left[f\left(\right.\right.$ rich-man, $\left.\left.h_{1}\right)=x\right]$ does contain an occurrence of a variable that is bound by the universal quantifier ' $V h_{1}$ ', thus it picks up different rich men across different teleological alternatives, and the selected man is said to be a banker on the corresponding teleological alternative. This too seems to correspond to the relevant interpretation of the discourse.

\subsection{THE STATUS OF THE SUPERVALUATIONAL MECHANISM AND THE INTERACTION BETWEEN PRAGMATICS AND SEMANTICS}

On the view that I have advocated, the supervaluational mechanism accounting for the presence of a universal quantification over possible histories in the truth conditions f a will-sentence is conceived of as pragmatic in nature. One might feel tempted to consider this mechanism as an instance of a top-down pragmatic process, comparable to those cases that have sometimes been described in the literature as free enrichment (Recanati 2001, 2004). The outcome of the supervaluation of a will-sentence, however, would not be correctly described as the result of a process of free enrichment, as I show below.

Consider sentence (46) below (the same as (34)): the proposition which is semanlically expressed by this sentence in a context $c$, relative to an assignment $g$, is the lunction from world-histories to truth-values given in (47) (standard semantic type Iunction from world-histories to truth-values given in (47) (standard semantic type $-8,1>$ ). No matter whether the con in (48)) or not (as in (49)), the truth conditions of (46) the circumstance parameter (as in (48)) or not (as in (49)), the truth conditions of (46) arc obtained through the same proposition (47), being uniquely due to the fact that, in the former conditions in (48) and those in (49) being uniquely due to the fact that, in the forme case, the proposition is required to hold of the parter case, it is required to hold of of the circumstance parameter, whereas, in the latter ca

6) John will marry a blond woman.

(17) $\|(46) \rrbracket_{\mathrm{c}, \mathrm{g}}=\lambda h .\left\{\mathrm{c}_{t} \leq \mathrm{s} \mathrm{g}\left(\mathrm{s}_{k}, h\right)\right\} \exists \mathrm{x}\left[f_{\mathrm{c}}\right.$ (blond-woman, $\left.\mathrm{g}\left(\mathrm{s}_{k}, h\right)\right)=\mathrm{x} \wedge$ marry $\left.\left(\mathrm{g}\left(\mathrm{s}_{k}, h\right), \mathrm{John}, \mathrm{x}\right)\right]$

(48) $\|(46) \rrbracket_{\mathrm{C}, \mathrm{g}, h}=1$

iff $\left\{\mathrm{c}_{t} \leq \mathrm{s} \mathrm{g}\left(\mathrm{s}_{k}, h\right)\right\} \exists \mathrm{x}\left[f_{\mathrm{c}}\left(\right.\right.$ blond-woman, $\left.\mathrm{g}\left(\mathrm{s}_{k}, h\right)\right)=\mathrm{x} \wedge \operatorname{marry}\left(\mathrm{g}\left(\mathrm{s}_{k}, h\right)\right.$, John, $\left.\left.\mathrm{x}\right)\right]$

(10) $\|(46)\|_{c, g, c_{w}}=1$

iff $V h_{1}\left[h_{1} \approx \approx_{c l} h_{0} \rightarrow\left\{c_{1} \leq \mathrm{s} \mathrm{g}\left(s_{k}, h_{1}\right)\right\} \exists \mathrm{x}\left[f_{c}\right.\right.$ (blond-woman, $\left.\mathrm{g}\left(\mathrm{s}_{k}, h_{1}\right)\right)=\mathrm{x}$ $\left.\left.\wedge \operatorname{marry}\left(\mathrm{g}\left(\mathrm{s}_{k}, h_{1}\right), \operatorname{John}, \mathrm{x}\right)\right]\right]$

Whis shows that the supervaluational strategy actually does not enrich the proposition temantically expressed by the sentence, which is the same before and after the supervaluation has taken place, Accordingly, on my analysis, the modal flavour characterizing a will-sentence could not be described as the result of a process of free enrichment. 
The point remains that the supervaluational mechanism belongs to the pragmatic domain. One might then wonder why this mechanism is not optional, unlike other more familiar cases of pragmatic processes (e.g. those underlying the generation of implicatures). ${ }^{31}$ I suggest that the extent to which this mechanism is not optional matches the extent to which our talks about the future confront us with a plurality of possible outcomes. Since we have assumed that the default situation in human conversations has the context leaving it undetermined what future will become actual, ou expectation is that a universal quantification over histories will be triggered whenever a linguistic expression (be it will, be going to, the simple present, or the progressive) is used in such conversations to refer to some future eventuality. ${ }^{32}$

\subsection{CONCLUSION}

In this chapter I have considered two main empirical issues concerning the semantics of will-sentences, namely Stalnaker's Asymmetry and modal subordination readings in Karttunen-type discourses with will. The former prima facie points to drawing a clearcut distinction between will and modal verbs like want, to the effect that will would not license non-specific indefinite objects. The latter points in the opposite direction: will seems to pattern like want in certain contexts, allowing for a nonspecific interpretation of an indefinite object. This unexpected fact suggests that a modal feature is perhaps present in the interpretation of a will-sentence. I have made a theoretical proposal that tries to profit as much as possible from both Stalnaker's and Karttunen's lessons: will acts semantically as a tense, not as a modal, hence it doesn't contribute a quantifier over modal alternatives by itself; a modal feature, however, is introduced in the interpretation of will-sentences through a supervaluational strategy that universally quantifies over historical alternatives representing the possible futures. The fact that the universal quantification over modal alternatives is not part of the semantics of will has been shown to have some natural consequences (in primis, the lack of scope interactions) that ultimately contribute to explain some basic facts at the origin of Stalnaker's Asymmetry. On the other hand, the fact that a modal universal quantification is there anyway when a will-sentence is interpreted has been shown to have consequences with respect to the possibility of modal subordination readings in Karttunen-type discourses with will.

A property of the semantic approach that I have proposed is that, since the modal feature characterizing the interpretation of a will-sentence does not come as part of

31 Thanks to the editors for raising this question and for suggesting the line of answer sketched in the text.

${ }^{32}$ White limits of space prevent me from discussing the semantics of other marken of futurity in English (let alone in other languages), I refer the reader to Copley (2009a) for an extenaive nitudy in which linguistic expressions of future reference are argued to involve univeral quantification over historien the semantics of will but as a consequence of the branching structure of the future, the modal behaviour of will is not viewed as an idiosyncratic property of this tense marker. In fact, a prediction that we can make on this approach is that necessity modal interpretations of the future tense should be available cross-linguistically. This prediction, as far as I can tell, has broad empirical support, and is confirmed even by languages which have a full-fledged synthetic (inflectional) future, like Italian.

Finally, it would be interesting to consider the relative merits of the proposed analysis vis-à-vis one which treats will as a necessity modal in accounting for cases where will interacts with modal adverbs of varying quantificational forces, as are discussed by Kissine (2008a). Some relevant examples of this phenomenon are (50) and (51):

(5o) Some of us here today will possibly have lost infants and young children from our own families. ${ }^{33}$

(51) It will hardly have gone unnoticed that Step 9 has been crammed with do's and don'ts, all worthy of close revision. ${ }^{34}$

If will were lexically a modal, it would be natural to regard such examples as instances of modal concord (in the sense of Geurts and Huitink 2006), but then the necessity modal analysis would face a difficulty in accounting for the co-occurrence of a neceswity modal with modal adverbs characterized by such diverse quantificational forces as the ones in (50) and (51). My expectation is that the analysis proposed in this paper would do better than a necessity modal analysis in providing an account of cases like (50) and (51). An attractive possibility would be to analyse the adverbs possibly and hardly in these examples as modal operators that quantify over the same modal alternatives that would otherwise be universally quantified over by the supervaluational itrategy if the will sentence were not adverbially modified. I leave the task of developing this line of analysis for a future occasion.

\subsection{ACKNOWLEDGEMENTS}

I 1 m indebted to Nicholas Asher, Michel Aurnague, Cleo Condoravdi, Graham Katz, Inidora Stojanovic, and Sandro Zucchi for discussion, and to an anonymous OUP revicwer for several important comments that enabled me to improve this paper. Detailed and generous comments from the volume editors Mikhail Kissine and Philippe De Brabanter were also of great value. Many thanks to Elizabeth Coppock, Steven Moore, and Jesse T'seng for their precious help with the English examples.

4 from beehive govt nz the oflicial websife of the New Zealand Government, 28 May 2004 Shttp:ll

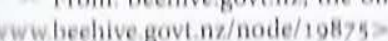

14 from I en Weinrelch, Heven Steps to Brand Heaven, Kogan Page Publisher, 2001. 